\title{
The ontology of resistance between power and knowledge
}

\author{
Hanan Muneer Al Sheikh*, Al Ahliyya Amman University Jordan, Amman, Jordan
}

\section{Suggested Citation:}

Sheikh, H. M. A. (2021). The ontology of resistance between power and knowledge. Global Journal of Sociology: Current Issues. 11(1), 28-36. https://doi.org/10.18844/gjs.v11i1.5455

Received from January 15, 2021; revised from February 22, 2021; accepted from April 10, 2021. Selection and peer review under responsibility of Prof. Dr. Mustafa Gunduz, Cukurova University, Turkey. C2021 Birlesik Dunya Yenilik Arastirma ve Yayincilik Merkezi, Lefkosa, Cyprus.

\begin{abstract}
The ontology of human resistance accentuates its existence through several expressive means with the most important being Art; as art transforms the question of resistance into a self-practice that starts with the artists and transfers between the inside and the outside in a continuous, creative and effective mutual relationship in order to emphasise the battle of existence conflict, ideology and Epistemology within the general framework of power. This philosophic analysis is based on the hypotheses of having a multilateral factor that continues with the past legacy on the one hand and interprets the present while overpassing it on the other, in order to create a state of creativity that represents the intellectual, emotional, cognitive and historical inventory, while posing a situation of continuous wondering among individuals and groups. This artistic state unifies the indicators of symbolisations and makes resistance represented in a contemporary visual discourse that rejects dominance, accentuates the identity and transforms the theoretical intellectual question into a practiced anthological act that is featured of permanent activity as a perpetual act towards liberation and reproducing self-existence.
\end{abstract}

Keywords: Art philosophy, resistance ontology, political caricature, photography.

* ADDRESS FOR CORRESPONDENCE: Hanan Muneer Al Sheikh, Al Ahliyya Amman University Jordan, Amman, Jordan. 


\section{Introduction}

This research paper aims at instilling an intellectual structure that accentuates the relationship between the dilemma of knowledge and power and the consequences of the human, social and creative phenomena that transform into a discourse criticising colonisation and emphasising continuous existence of the resistance concept. The ontological question here is about the first defect of resistance, which is colonisation, then transforms into the conditional defects related to time and place, which all determine the power practices represented in dominance, oppression and imposing power within the framework of societal knowledge. This affects the form of resistance and selfpractice, whereas ideology becomes completely related to the different types of power (religious power, state power and occupation power), with the determination and constriction of the tribal and paternal power of the social structure. This makes the researcher's duty in this field more difficult, whereas the research is responsible for two aspects: first, determining and understanding the individual / collective attitude in the visual creative discourse, and the second is researching the core of human existence of the indigenous community and their right of sustainability.

We may here pose the following question: Can the resisting artist engage in that controversial intellectual dilemma without self and other (colonist) consciouses and by recognising ego along with the individual and collective identity?

If the answer is yes, then we separate the artist self from the subject matters existing around the world, and this denies the concept of conscious that we are seeking for herein. How can an artist be resistant when not recognising his human identity through ego, collective and other consciouses? Giving the resisting artist the character of citizenship necessarily requires having the attributes of attendance and absence, doubt and certainty, as this is part of the mind and existence structure that gives the individual a human identity. Accordingly, the answer for that question might include several and varied debates to be discussed later on in this research paper.

\section{Visual discourse in art and limits of resistance}

We shall be indicating first that the discourse discussed herein is not the discourse for criticising colonisation only; but a philosophic artistic discourse that is renewed within epistemology, as it is not limited by time and place rather than running through the wide existence and human understanding. Resistance here is a phenomenological act with open horizons to the hermeneutic approach that keeps posing questions and discussing the core of the power and knowledge concepts that are companying conflict between colonists and indigenous community.

Basically, speaking of the visual discourse is partly speaking about a relationship between artist and recipient within specific styles, and such styles are the 'fields of association, conjunction and organisation. The scope of style hereunder is mainly cultural; as styles are specific methods of the previously seen, read and done, and the style is the form of that act previously done and formulating the world' (Barthes, 2009). The artistic style in the visual discourse is necessarily cultural, as it is the cognitive, social, temporal, ideological and communication styles; it is the group of styles formulating a strong liberation cultural style. Accordingly, what is important in this discourse is believing in common international liberation values, while maintaining the local privacy that reflects core of the cultural situation that presents such continuous conflict between the colonist and indigenous citizen.

Therefore, the reflection of that core is achieved when the ego is always of the type 'us', since the ego that believes in being individual and indigenous is crowded of the other egos, while the 'us' includes 'them' and 'you' (Zuraiq, 2019). This also makes the artistic discourse indirectly a powerful one, which is determined by the strategy pf knowledge and will. It is a network of the relationships of strength, dominance and control that started with the first existence of colonisation, whereas the colonisation power had clear attributes 'such as separating the connected, drawing borderlines, strict observation, ready decisions, and imposing domination with regards to education, health and 
demography' (Abu Lughod 2020). At this point, the colonisation power starts to control the nature of discourse, self and other consciouses through icons determining the historical and geographic scope, which led various artists and intellects to proceed in the concept of difference and variation to ensure ego discourse and local identity, thus the continuous conflict over power is a cognitive conflict that may only be overpassed by resistance as 'whenever power exists there will be resistance' (Foucault, 1990).

We are talking here about the varied discourses; although the general discourse is the discourse of art embodied in the achievements of Naji Al-Ali and Ahmad Al-Safarini, the tools, techniques and trial pathways in each case are different. The intersecting, diverging and attracting stories are all similar in embodying freedom, liberation from oppression and prevention along with power and domination, while also being a fulfilment of knowledge legitimacy; as if the artistic discourse was the one determining social relation between discourse parties. 'Each knowledge, whether presented in a narrative or storytelling manner, is directly indicating things in the external world' (Lyotard, 1984). Thus, we shall be assisted by the story when we need to understand the narrative, artistic, poetic and fictional discourse, and this transforms us from the manipulations of language into the manipulations of discourse that enables us of moving between them while maintaining coherence of things.

Accordingly, we may say that the artistic discourse is 'a discourse that embodies knowledge, thus embodies strength, and a person having knowledge can have strength for determining streamline of meanings and determination of others. Accordingly, the world consists of thousands of strength relations, and each strength creates resistance' (Craib, 1999). 'Understanding power within the levels of individual, society and state makes the power of the cultivated individual a self-power that is autologous, creating its own laws without receiving them externally, and when respecting such laws; it is only respecting itself, which was expressed by Cunt as independence. Here appears the relation between knowledge, society and state, which is a mean and purpose relation' (Lyotard, 2016). Here the techniques of self-practice are introduced, in which the inside is the outside and the outside is the inside. Such techniques may never be carried out but through knowledge and power, whereas the strategic dimensions transform 'self-practice into self-reproduction' (Dolouse, 1999).

\section{Self-practice and power practice}

I can say that the previous ideas are gathered in a complicated formula, as knowledge is correlated to power, and it is the basis of practice, while practice is an act for the conscious existence and knowledge, which means that fields are correlated and cohered and that proposes the following questions: Is that artistic discourse determined only by the political aesthetic scene? Does that discourse include concepts like will, strength, desire of survival, co-existence, reform, goodness and justice? Questions transform such controversy into political, ethical, humanitarian and philosophical discourses, gathered by the same principle, which is change, transformation and progress towards the absolute, but what is the actual drive and guarantee for reaching the absolute that is motivating change? It is the idea of revolution. 'Revolution is not rebellion or disobedience; rather than being a call for exceeding the usual ordinary, since there are ideologies giving it the attributes of universal, mindful and actual' (Lyotard, 2016).

This actual mindful attribute motivates an important issue, as the artist remains in a state of concern between two consciouses: the conscious that is regulated by the laws of mind and logic and considers it impossible to stop conflict between colonists and indigenous citizens and the conscious that looks for absolute justice that does not accept breaching the material, intellectual and cultural properties only by strength. The model of practiced power just mentions is 'the power existing in the daily and partial practices and in the subject matters outside social contract, i.e., in the relations not having any contract' (Foucault, 2007). And it is under the 'continuous conflict and not contract that properties are waived and controlled. Power is practiced more than being owned. Holding it is not a privilege, but preparation, tactics and maneuver' (Foucault, 1990) 
This leads us to a conclusion with two branches: either the artist self is separate from the act done, i.e., he chooses act subject matter based on a stable knowledge, and this restricts the philosophical intellect, as we may not follow a stable knowledge since it will make us let go of looking for knowledge and denies artist being an ontological creature, having self- conscious within others conscious. The second branch is that the artistic act is necessarily central, while the act of resistance is part of the deep-rooted, upgraded, changing, independent and existing discourse, and this branch makes the artistic practice as an option and act between the self and others, which is some kind of process in completing the concept of resistance.

By referring to the context, there is a number of reasons motivating me for finding this philosophical approach between the caricaturist Naji Al-Ali (1987-1936) and the photographer Ahmad Al-Safarini (1946); the first is the different methodology of both artists; as the one of Naji Al-Ali is a social, critical semiotic one that indicates strict rejection of obedience and sharp criticism of the power systems followed in the State of Palestine and the status of displaced people, whereas the methodology adopted by Al-Ali is expressed by self-conscious through others' conscious, which made his exertions create a general state of continuous enquiry and collective conscious. The methodology followed by photographer Ahmad Al-Safarini is an empirical one that sought studying situation from self and space-time perspective, within retesting the concepts and values and confirming their core and sustainability. Diversity in methodologies makes artistic exertions like caricature and photography as a procedural tool that enables us of tracking the study subject matter and conjugating the theory with practice and reflection.

The second reason is accentuating that the artistic work built on knowledge of Naji Al-Ali, which became in core an ontology that is combined with the past, present and future, while forming the path of struggle, rejection of oppression and reviving resistance in the popular intellect, which led to varied styles in the different technical fields (Figures 1-3). The photographer differs in this approach in having a tool-wise mindset that is focussed on discovering the purpose of the objects existing around, even if was not able to cause a material change in the social conscious, but can adapt with the concepts and test them. At the same time, it is not absolutely tool-wise; as we reject the idea that makes the artist a prisoner of the tool mindset only, since the self has other aesthetic, objective and cognitive dimensions. Accordingly, what photography provides is a communication act of two forms; the first includes teleological (causalistic) acts and the other seeks 'achieving understanding' (Rasmussen, 1990).

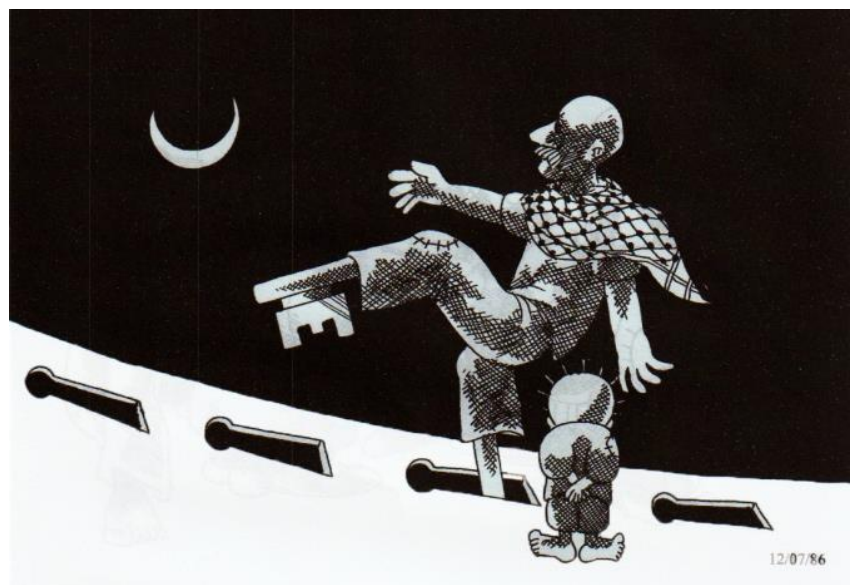

Figure 1. Naji Al Ali (1986) 

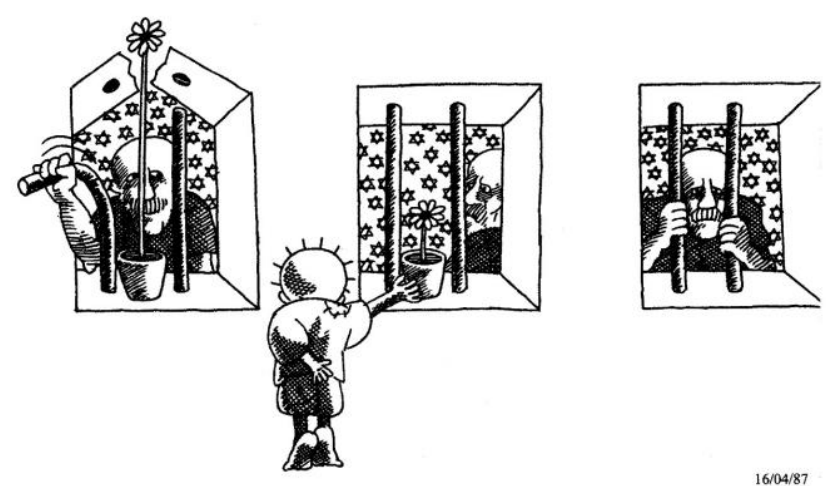

Figure 2. Naji Al Ali (1987)

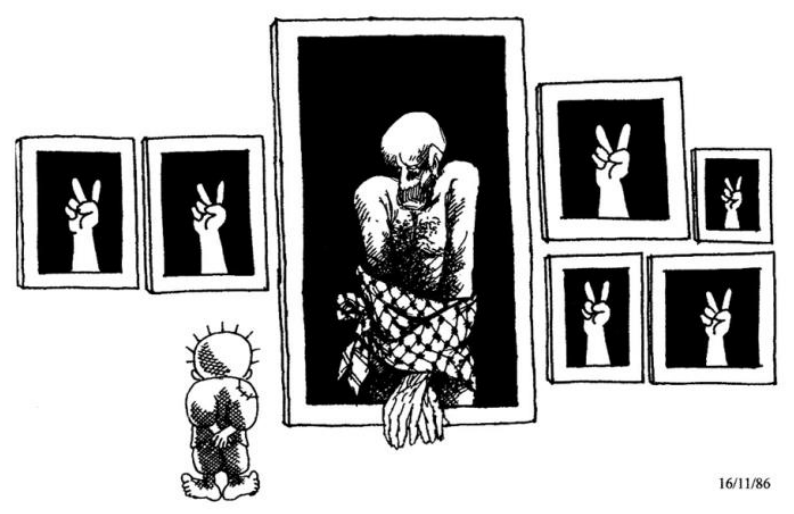

Figure 3. Naji Al Ali (1986)

We shall be clarifying here that the intended photography exertions are abstract ones and not documentary or journalistic with explicit resistance, rather than being realistic and resulting from a deep contemplation of the details only seen by the artist in earth, trees and all other places, which is related to his conscious, recognition and history. What we are looking and accentuating here is the ontology of resistance in the collective conscious, and its representation through subconscious of the cultured artist seeking knowledge and adaptation with the intellectual and cultural system (Figures 47). Although the photographer does not geographically live in his homeland; he is motivated by the spirit of past struggle and future resistance, whereas conscious and subconscious is determined here by self-attribute and not geometric-attribute, and 'dream expands to become an experience keeping it alive and giving it its material clarity' (Bachelard, 1984), 'human is the case here' (Kanafani, 2015), while homeland is human and human is indeed homeland.

The scene repeating by the repetition of characters and general common state between the exertions of both artists Al-Ali and Al-Safarini, accentuates the continuous act; as practicing that in a reflective artistic context makes us pass by three main phases that led to emphasising the resistance ontology, renewing knowledge and determining traits of the dominant power. Such phases include the phenomenology of the critical political scene provided by Al-Ali through his artistic tools during the twentieth century, which actually started with the appearance of symbols, connotations and referrals that were used to provide a logical justification while documenting the political events related to understanding the colonisation contexts. This provided a causality space-time logical sequence for the Palestinian people, while forming a collective opinion, which is the second phase, in which we are guided to the purpose sought from liberation, through the societal presence and formulation of a common sense between individuals and groups. Continuity of the resistance ontology 
scene makes this 'subject matter joining other human subject matters, while merging such context within the huge inventory of the ideologies handling destiny of identity, subsistence, history and right of return'. The third phase is the current one, in which individuals in all fields are seeking to form varied opinions that are again referring to knowledge and dominant power, which were the first motive of that thread.

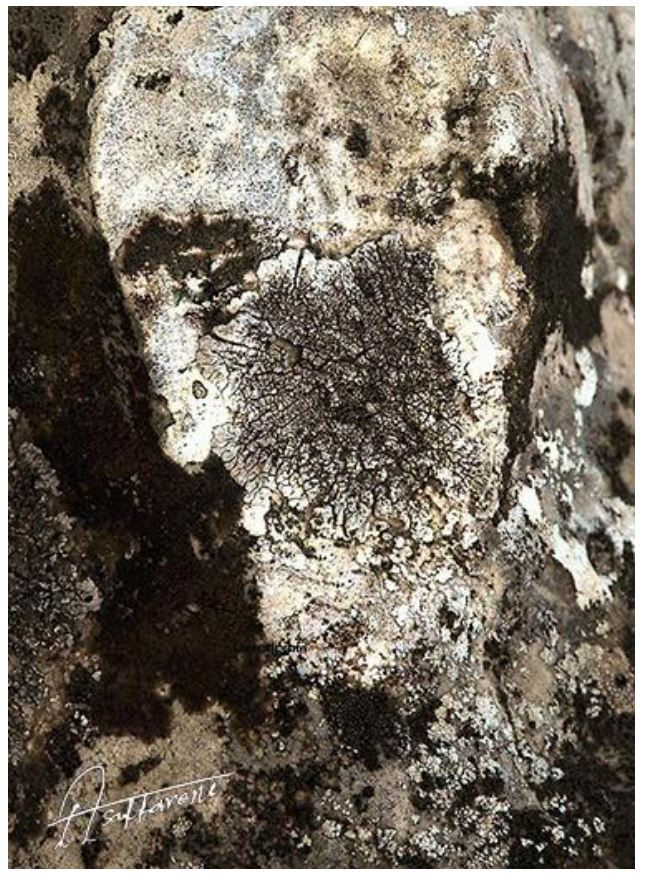

Figure 4. Ahmad Al Safarini (2012)

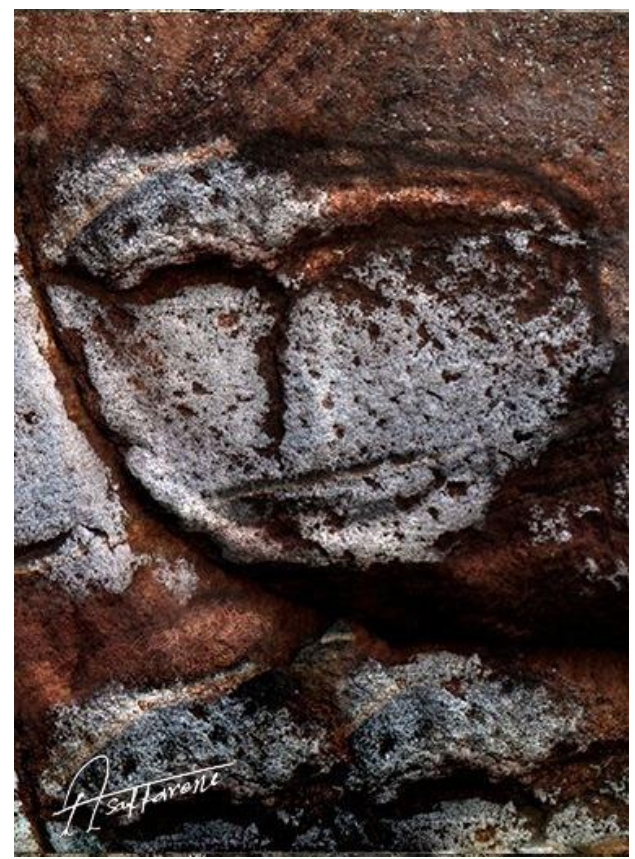

Figure 5. Ahmad Al Safarini (2012) 


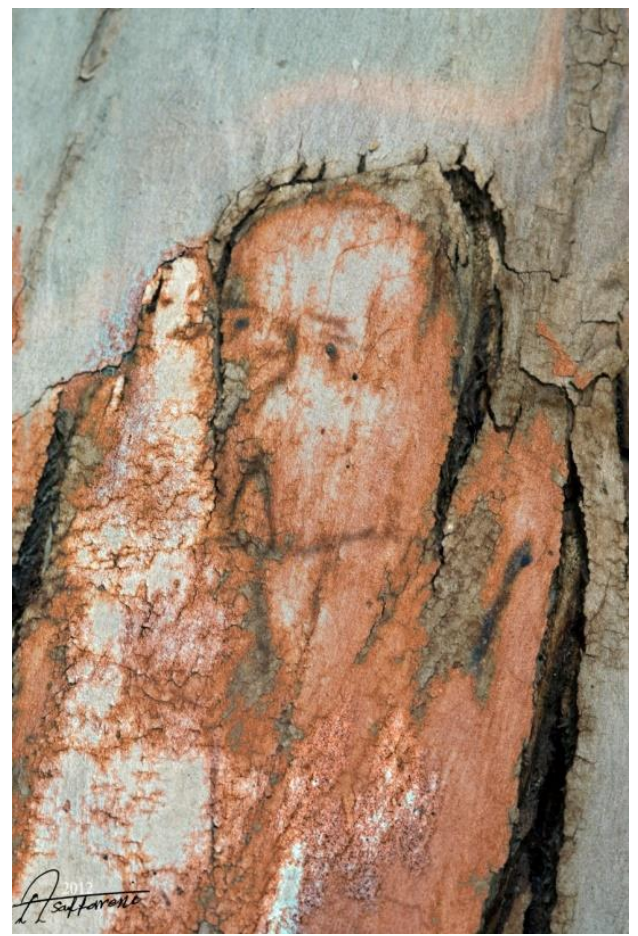

Figure 6. Ahmad Al Safarini (2013)

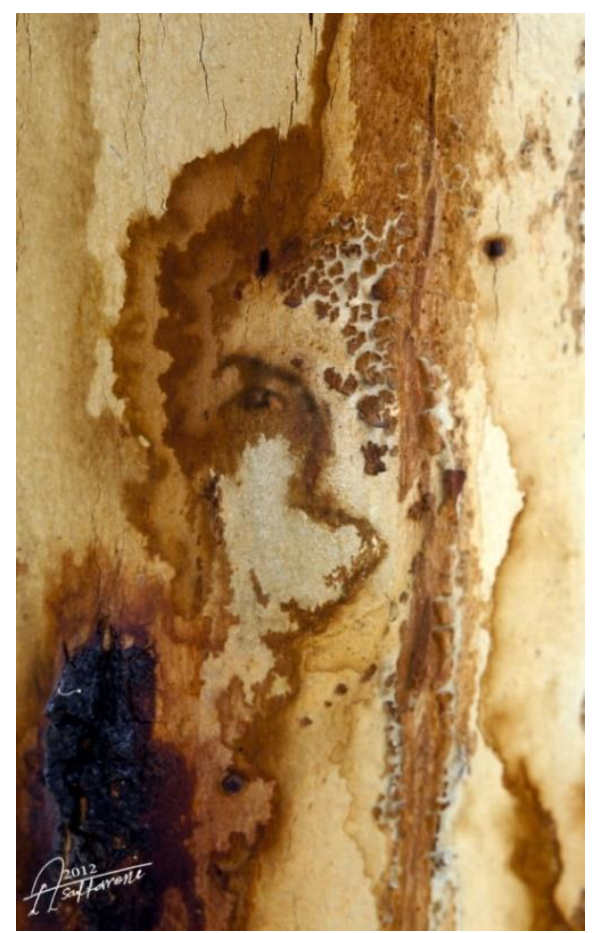

Figure 7. Ahmad Al Safarini (2013)

The existence that I mean here in the three phases 'became current and innovated as a result of the communicative act and having a strong society that is capable of creating a specific issue and public opinion leading to the partial or total change', in other words, 'the strength of communicative impact transforms through the legislation process into an administrative executive strength' (Habermas, 
1996). This leads to the conclusion that the connotations unified in the exertions of caricaturist Naji AlAli, which represented criticising colonisation and resistance intuition, became a cognitive and emotional inventory of groups, thus part of conscious and subconscious and an agreed factor that may be formulated and borrowed in the different contexts.

Therefore, we are speaking here about two ontological issues in the artistic exertion within the ego/ other system; as on one hand the artistic exertion is individual and depends on 'the artist vision and capability of overcoming, creating and renovating, while on the other hand it determines the meaning of the lived reality and maintains the cultural and societal heritage that represents genuine past' (Williams, 1998). Accordingly, we have two states: the first represents in the exertions of artist Naji AlAli, who formulates group dreams and unifies meanings and huge national projects, and the second represents in the exertions of artist Al-Safarini who stays in the continuous enquiry about such values and meanings.

\section{Conclusion}

Colonisation criticism discourse is varied and takes various forms that might be artistic, cultural, political, economic, philosophical or religious. But whatever the form of discourse, it is continuous and sustainable while having the attribute of total necessity of self and other conscious. Conscious is individual and collective at the same time, and renews in the conflict of knowledge and power, thus emerging the concept of resistance within a complicated formula with confused concepts of will, strength, co-existence, right of return and justice. The resistance ontology appears in the artistic exertions by the continuous combination with the past, present and future for ensuring the path of struggle and rejecting obedience within three important phases; first the phenomenology phase that starts with semiotic act that determines political and popular connotations, second is seeking liberation and determination of objective through the common collective sense and third is rereading the scene repeatedly within the new knowledge and power concepts. It is an infinite series that is seeking to maintain the cultural and societal herniate while accentuating that art is a genuine innovated discourse and that the cause is human.

\section{References}

Abu Lughod, L. (2020). Imagining Palestine's alter-natives: Settler colonialism and museum politics, critical inquiry. The University of Chicago.

Bachelard, G. (1984). (H. Ghaleb, Trans) (p. 83). University Publishing and Distribution House.

Barthes, R. (2009), Textual analysis (Trans A. -S. Abdulkabeer, A. -T. Dar) (p. 110).

Craib, I. (1999). Social theory: From parsons to Habermas (G. Mohammad, A. -M. Alam Trans) (p. 347). Edition 244 Kuwait.

Dolouse, J. (1999). Empiricism and subjectivism: Research in human nature according to Hillaume (A. H. Osama Trans). Arab Publishing and Distribution House.

Foucault, M. (1990). Discipline and punish: The birth of the prison (M. Ali Trans). National Development Center.

Foucault, M. (2007). Security, territory, population, lectures at the College de France (1977-1978), (B. Graham, Trans) (p. 117). Palgrave Macmillan.

Habermas, Y. (1996). Between facts and norms contributions to a discourse of law and democracy (R. William, Trans.) (p. 299). The MIT Press Cambridge.

Kanafani, G. (2015). Returning to Haifa novel. Remal Publications.

Lyotard, J. -F. (1984). The post modern condition. University of Minnesota Press. 
Sheikh, H. M. A. (2021). The ontology of resistance between power and knowledge. Global Journal of Sociology: Current Issues. 11(1), $28-36$. https://doi.org/10.18844/gjs.v11i1.5455

Lyotard, J. -F. (2016). In the meaning of after modernity: Texts in philosophy and art (L. Al-Said Trans) (p. 10). Arab Cultural Center.

Rasmussen, D. M. (1990). Reading Hebermas (p. 27). Basil Blackwell.

Williams, R. (1998). The analysis of culture in cultural theory and popular culture (pp. 48-57). University of Georgia Press.

Zuraiq, R. (2019). Edward said and role of the intellect (p. 28). Palestinian Studies Magazine, Edition 118. 